\title{
Effect of dairy product environment on the growth of Bacillus cereus
}

\author{
E. Tirloni, ${ }^{* 1}$ E. Ghelardi, † F. Celandroni, $†$ C. Bernardi, ${ }^{*}$ and S. Stella* \\ *Department of Health, Animal Science and Food Safety, Università degli Studi di Milano, Via Celoria 10, IT-20133, Milan, Italy \\ †Department of Translational Research and New Technologies in Medicine and Surgery, University of Pisa, Via San Zeno 37, IT-56127, Pisa, Italy
}

\begin{abstract}
$\mathrm{pH}$ is one of the most important parameters to manage bacterial replication in foodstuffs. In this study, the ability of 2 Bacillus cereus strains, 1 clinical human isolate (GPe2) and 1 isolate from a dairy product (D43), were investigated for in vitro growth at different $\mathrm{pH}$ values (from 3.5 to 7.5 ) at 2 temperatures (15 and $37^{\circ} \mathrm{C}$ ), showing their ability to grow from 5.5 to 7.5 and from 5.0 to 7.5 , respectively. The ability of spores of these 2 microorganisms to germinate in different typologies of dairy products (unflavored yogurt, Taleggio cheese, mascarpone cheese, and raw and pasteurized milk) was also investigated by inoculating the spores and maintaining the products at $15^{\circ} \mathrm{C}$. No growth was observed in yogurt, likely due to the combined effect of low $\mathrm{pH}(<5)$ and the presence of natural microflora. An inhibitory action of the natural microflora on the growth of B. cereus was also hypothesized for Taleggio cheese and raw milk, as these substrates were characterized by a high natural lactic acid bacteria population and permissive $\mathrm{pH}$ values (5.8/6.8 in Taleggio cheese, $>7$ in raw milk). In pasteurized milk and mascarpone cheese, where $\mathrm{pH}$ was not restrictive for $B$. cereus growth and where no significant natural microflora was present, growth occurred rapidly up to loads close to 7 $\log \mathrm{cfu} / \mathrm{g}$.
\end{abstract}

Key words: $\mathrm{pH}$, milk, cheese

\section{INTRODUCTION}

The Bacillus cereus group includes 8 species of ubiquitous gram-positive spore-forming bacteria, very similar from a genetic point of view but characterized by extremely specialized behaviors. This group includes $B$. cereus sensu stricto, which is frequently associated with severe food poisoning episodes because of its ability to produce toxins such as cereulide, cytotoxin K, hemoly$\sin \mathrm{BL}$, and nonhemolytic enterotoxin. A total of 453 foodborne outbreaks were reported in the period 2007

Received April 3, 2017.

Accepted May 27, 2017.

${ }^{1}$ Corresponding author: erica.tirloni@unimi.it to 2014 in the European Union with B. cereus identified as the causative agent, with more than 6,600 human cases and a hospitalization rate of $5.3 \%$ (Kotiranta et al., 2000; EFSA, 2016).

Foods that may represent a risk for B. cereus include ready-to-eat products based on rice or pasta, dairy products, flavorings, pastry, and vegetables, and those included in the subcategory called refrigerated processed foods of extended durability (Wijnands et al., 2006).

Milk, as produced from healthy cows, could be considered free of bacteria, but farm and dairy environments may be a source of contamination especially during milking and cheese production. In particular, $B$. cereus was previously recognized as responsible for raw milk spoilage (Bartoszewicz et al., 2008); moreover, a concise risk assessment on $B$. cereus in the Netherlands predicted that almost $7 \%$ of pasteurized milk was characterized by loads of this pathogen above $5 \mathrm{log}$ $\mathrm{cfu} \cdot \mathrm{mL}^{-1}$ (Notermans et al., 1997). Although vegetative cells of $B$. cereus are not able to survive to pasteurization, spores are resistant to heat treatments, highlighting the possibility of their persistence in pasteurized milk. Bacillus cereus was also found in several dairy products, with different prevalence from 2 to $52 \%$, depending on the typology (Wong et al., 1988; Svensson et al., 2006; Spanu et al., 2016).

It is well known that $\mathrm{pH}$ is one of the most important parameters used to manage bacterial replication and today low $\mathrm{pH}$ foods are widely produced and consumed as they guarantee bacterial stability. Dairy products are characterized by various substrate acidity levels that may differently affect the growth of $B$. cereus, whose presence results from the contamination of milk or a postprocess contamination. Recently, the combined effect of anaerobiosis, low $\mathrm{pH}$, and cold temperatures on the growth ability of $2 \mathrm{~B}$. cereus strains was assessed, highlighting that at $10^{\circ} \mathrm{C}$ growth of psychrotrophic strains occurred at $\mathrm{pH} \geq 5.7$ in anaerobiosis, whereas aerobic growth occurred when $\mathrm{pH}$ was $>5.4$ (Guérin et al., 2016).

Also, the ability of $B$. cereus to cause food poisoning (e.g., diarrheal syndrome) is strictly related to its ability to resist to low $\mathrm{pH}$, as the production of enterotoxins 
is a consequence of the survival of $B$. cereus spores and vegetative cells ingested with food through the stomach reaching the small intestine alive.

The aim of the present study was the assessment of growth ability of 2 strains of $B$. cereus (one isolated from a human infection and one from a dairy product) in broths at different $\mathrm{pH}$ (from 3.5 to 7.5). Moreover, the ability of these 2 strains to grow in various dairy products characterized by different $\mathrm{pH}$ and substrate conditions was also evaluated.

\section{MATERIALS AND METHODS}

\section{Bacterial Strains and Characterization of the Isolates}

In the present study, 2 B. cereus strains were used. The first strain was a human clinical isolate (GPe2), previously characterized for the ability to grow within the thermal range from 15 to $37^{\circ} \mathrm{C}$ and for virulence characteristics (Celandroni et al., 2016; Tirloni et al., 2017). The second strain (D43), previously isolated from a dairy product (Taleggio cheese) was identified by matrix-assisted laser desorption/ionization timeof-flight (MALDI-TOF) MS as previously described (Celandroni et al., 2016).

The D43 strain was characterized to identify its thermal range of growth. The strain stock was kept frozen at $-80^{\circ} \mathrm{C}$ in Microbank Cryogenic vials (Pro-Lab Diagnostics UK, Merseyside, UK) until a loop of bacterial culture was transferred into nutrient broth tubes (70122, Sigma, St. Louis, MO) and incubated at $37^{\circ} \mathrm{C}$ for $24 \mathrm{~h}$. Cells were harvested in exponential growth phase, defined as a relative change in optical density (OD) of 0.05 to 0.2 at $540 \mathrm{~nm}$ (6320D spectrophotometer, Jenway, Staffordshire, UK). Cell concentration of the suspension was calculated by counting under a phase-contrast microscopy (BA 310, Motic, Barcelona, Spain) and was diluted in sterile saline water $(0.85 \%$ $\mathrm{NaCl}$ ), to obtain a concentration of $2 \log \mathrm{cfu} \cdot \mathrm{mL}^{-1}$. Afterward, $0.1 \mathrm{~mL}$ of the suspension were plated in duplicate onto Nutrient Agar (Sigma 70148), and incubated at different temperatures $(5,7,10,15,20,37,41$, 45,50 , and $55^{\circ} \mathrm{C}$ ) and checked twice per day for colony formation for up to $15 \mathrm{~d}$.

\section{Determination of Growth Ability of B. cereus Strains in Broth at Different pH Values}

The 2 strain suspensions were prepared from the frozen stocks as described in the Bacterial Strains and Characterization of the Isolates section; then, they were counted and diluted to reach a starting concentration of $2 \mathrm{log} \mathrm{cfu} \cdot \mathrm{mL}^{-1}$. Aliquots of $0.1 \mathrm{~mL}$ of each strain suspension were inoculated into $10-\mathrm{mL}$ tubes contain- ing nutrient broth at different $\mathrm{pH}(3.5,4.0,4.5,5.0$, $5.5,6.0,6.5,7.0$, and 7.5) obtained adjusting the initial value $(7.5 \pm 0.2)$ with $\mathrm{HCl}$. At the time of inoculation (T0), OD was measured and the tubes were then incubated at 2 different temperatures $\left(15\right.$ and $\left.37^{\circ} \mathrm{C}\right)$ in duplicate. At fixed times $[24,48,72,96,120$ (T5), 144, 168, and $192 \mathrm{~h}$ from inoculation], OD was newly measured. Blank (not inoculated) broth series were also prepared for each $\mathrm{pH}$ value and incubated at the 2 storage temperatures.

\section{Growth Potential of B. cereus GPe2 and D43 in Dairy Products}

Harvesting of Dormant Spores. Spores of the 2 $B$. cereus strains were produced separately on fortified nutrient agar (Senesi et al., 1991) added with sporulation salts: $\mathrm{NaCl}\left(5.0 \mathrm{mg} \cdot \mathrm{mL}^{-1}\right), \mathrm{CaCl}_{2},\left(0.1 \mathrm{mg} \cdot \mathrm{mL}^{-1}\right)$, and $\mathrm{MgSO}_{4} \cdot 7 \mathrm{H}_{2} \mathrm{O}\left(2.0 \mathrm{mg} \cdot \mathrm{mL}^{-1}\right)$. Roux bottles with 150 $\mathrm{mL}$ of the above medium were inoculated with $2.0 \mathrm{~mL}$ of bacterial suspension $\left(\sim 10^{8} \mathrm{cfu} \cdot \mathrm{mL}^{-1}\right.$ in sterile distilled water). After incubation at $37^{\circ} \mathrm{C}$ for $20 \mathrm{~d}$, spores were scraped from the surface of the medium with a sterile stirrer and washed 5 times by centrifugation $(10,640 \times g$ for $10 \mathrm{~min} / 2^{\circ} \mathrm{C}$ ) with ice-cold sterile distilled water. To remove residual vegetative cells, each spore suspension was heated at $80^{\circ} \mathrm{C}$ for $10 \mathrm{~min}$ in a water bath. Then, the 2 suspensions were quickly cooled in ice, rewashed with ice-cold sterile distilled water, and conserved at $2^{\circ} \mathrm{C}$ until inoculation that was within $3 \mathrm{~d}$.

Challenge Tests with Inoculated Dairy Products. For challenge tests with GPe2 and D43 strains, 5 typologies of dairy products were considered: raw and pasteurized milk, mascarpone cheese (an Italian cream cheese coagulated by the addition of food grade organic acids), unflavored yogurt, and Taleggio cheese (a Protected Designation of Origin semisoft, washedrind, smear-ripened Italian cheese).

Spore suspensions, obtained as described in the Harvesting of Dormant Spores section, were diluted in sterile saline to reach a final concentration of about 5 $\log \mathrm{cfu} \cdot \mathrm{mL}^{-1}$ for each of the $2 B$. cereus strains. These suspensions were immediately used for the inoculation of aliquots of each of the 5 products in duplicate: briefly, spore suspension was spread onto the surface of Taleggio cheese in 5 spots and immediately was homogeneously distributed using a spatula; for yogurt, milk, and mascarpone, because of their nonsolid matrix, the spore suspension was distributed using a spatula.

To minimize changes in product characteristics, the inoculum volume did not exceed $1 \%$ of the final weight. Blank samples, inoculated with the same volume of sterile saline solution were also prepared. The inocu- 
lated and blank samples were then incubated at $15^{\circ} \mathrm{C}$. Temperature was constantly recorded by Escort iLog data loggers (Escort Data Logging System Ltd., Aesch Bei Birmensdorf, Switzerland).

Samplings were performed at the moment of inoculation and after $1,2,3$, and $5 \mathrm{~d}$ of storage in duplicate. For raw milk inoculated samples, analyses were performed at 1,2 , and $4 \mathrm{~d}$ of storage. Just after the inoculation, water activity $\left(\mathbf{a}_{\mathbf{w}}\right)$ of each product was measured (Hygrolab, Rotronic, Milan, Italy); at each sampling time, $\mathrm{pH}$ was measured (334-B, Amel Instrument, Milan, Italy), and microbiological analyses were performed. From each inoculated sample, $10 \mathrm{~g}$ of product was diluted 10-fold in chilled sterile diluent solution $(0.85 \%$ $\mathrm{NaCl}$ and $0.1 \%$ peptone) and homogenized for $60 \mathrm{~s}$ in a Stomacher 400 (Seward Medical, London, UK). Then, appropriate 10-fold dilutions of the homogenates were made in chilled saline. Bacillus cereus was enumerated according to the ISO 7932:2004 (ISO, 2004) method, by spreading onto mannitol egg yolk polymyxin agar and incubating at $30^{\circ} \mathrm{C}$ for $48 \mathrm{~h}$. For the enumeration of spores, homogenates were pasteurized at $80^{\circ} \mathrm{C}$ for 10 min before plating; then, plates were incubated at $30^{\circ} \mathrm{C}$ for $48 \mathrm{~h}$. Blank samples were analyzed at the same sampling times and lactic acid bacteria (LAB; ISO 15214:1998; ISO, 1998), lactococci (onto M17 agar incubated at $37^{\circ} \mathrm{C}$ for $48 \mathrm{~h}$ ), and B. cereus (mannitol egg yolk polymyxin agar) were enumerated.

\section{Statistical Analysis}

The data obtained from the $B$. cereus counts in milk and dairy products (expressed as $\Delta \log \mathrm{cfu} / \mathrm{g}$ between the sampling time and T0) were submitted to 2-way univariate ANOVA (SAS, version 9.4, SAS Institute Inc., Cary, NC) to reveal an eventual difference in the behavior of the 2 strains. Threshold values for statistical significance were set at $P<0.05$ and $P<0.01$.

\section{RESULTS AND DISCUSSION}

\section{B. cereus D43 Characterization}

The growth ability of D43 strain was assessed in solid culture medium. No growth was detected at temperatures below $15^{\circ} \mathrm{C}$, or above $42^{\circ} \mathrm{C}$, whereas evident colonies were observed in the range between 15 and $37^{\circ} \mathrm{C}$ at variable times (from $24 \mathrm{~h}$ at $37^{\circ} \mathrm{C}$ to $20 \mathrm{~d}$ at $15^{\circ} \mathrm{C}$ ). As reported by Guinebretière et al. (2008), B. cereus are characterized by a wide range of growth thermal abilities, with some strains also able to grow at refrigeration temperatures. The D43 strains grow in a specific mesophilic thermal range, but temperatures near the lower edge of the range can easily occur during cheese ripening and storage. The observed thermal range was the same as assessed for the GPe2 strain. This result gave the possibility to better evaluate the data obtained from further parallel trials with the 2 strains that come from different sources (dairy product or human clinical isolate). The importance of using a strain previously isolated from a similar matrix in experimental trials is well described for different pathogenic bacteria, and the positive effect of preadaptation on microbial survival and growth has already been observed (Leyer and Johnson, 1992; Shen et al., 2008; ANSES, 2014).

\section{Growth Ability in Broth at Different pH}

The ability of the $2 \mathrm{~B}$. cereus strains considered to grow at different $\mathrm{pH}$ was tested at 2 temperatures (15 and $37^{\circ} \mathrm{C}$ ); the results, expressed as increases in $\mathrm{OD}$, are presented in Table 1 . At $15^{\circ} \mathrm{C}$ B. cereus GPe2 grew from $\mathrm{pH} 5.5$ starting from d 5; a rapid growth was revealed between $\mathrm{pH} 6$ and 7.5 starting from d 4 (at $\mathrm{pH}$ 6.5 , a slight increase was observed from d 3 ). The same strain maintained at $37^{\circ} \mathrm{C}$ showed a fast growth immediately after the first day of storage at $\mathrm{pH}$ between 5.5 and 7.5, whereas OD increased at $\mathrm{pH} 5$ after $3 \mathrm{~d}$. At $15^{\circ} \mathrm{C}$ B. cereus $\mathrm{D} 43$ was shown to grow quickly, as for $\mathrm{GPe} 2$, from d 4 at $\mathrm{pH}$ between 6.5 and 7.5 ; also at $\mathrm{pH} 6$, growth occurred (more slowly) since d 4 . The D43 strain at $37^{\circ} \mathrm{C}$ showed a very fast increase in OD from the first day of storage at $\mathrm{pH}$ between 5.5 and 7.5, whereas at $\mathrm{pH} 5$ the increase was observed from the second day.

Summarizing the results obtained, both B. cereus strains grew very fast at $37^{\circ} \mathrm{C}$, the optimal growth temperature for bacilli, covering a range of $\mathrm{pH}$ (from 5 to 7.5 ) that likely occurs in dairy products. Also, if the temperature applied in this trial was not indicative for the production and storage of dairy products, it allowed us to define the maximum growth range of the 2 different strains, which was revealed to be the same. The temperature applied in the other trial $\left(15^{\circ} \mathrm{C}\right)$ was the minimum growth temperature for both the strains, but this value can be likely reached also during the production, ripening, and storage phases (especially during the warm season). The growth ability of the 2 strains was partially affected by the lower temperature, as growth was detected in a $\mathrm{pH}$ range between 5.5 and 7.5 and between 6.0 and 7.5 for GPe2 and D43 strains, respectively. This reduction in $\mathrm{pH}$ growth range should be carefully considered, as several dairy products are characterized by $\mathrm{pH}$ values near the lower growth limit. The wider range observed for D43 strain could be a hint of the adaptation of this strain, isolated from a dairy 
product ( $\mathrm{pH}$ of Taleggio cheese is generally around 5 to 5.5), to the acidic environment. Carlin et al. (2013) evaluated the growth rates of several strains covering the 7 main phylogenetic groups of Bacillus cereus sensu lato (as defined by Guinebretière et al., 2008), highlighting a range of minimum $\mathrm{pH}$ of growth between 4.59 and 4.96, depending on the group. The ability to grow at $\mathrm{pH}$ lower than 4.6 has previously been described (Claus and Berkeley, 1986; Raevuori and Genigeorgis, 1975), although the chapter about $B$. cereus published by the International Commission for the Microbiological Specifications for Foods indicated a $\mathrm{pH}$ equal to 5.0 as the limit for this microorganism (ICMSF, 2005), according to the results obtained in our experiments.

\section{Bacillus cereus Growth Ability in Dairy Products}

Bacillus cereus is frequently isolated from raw milk, and because of its ability to resist pasteurization treatments, it is of particular concern in the dairy industry, as the presence of diarrheal syndrome-causing strains in milk is well known (Granum et al., 1993; in't Veld et al., 2001). Moreover, their capacity to cause food spoilage and disease through the production of various toxins is well known (Stenfors Arnesen et al., 2008).

Different categories of dairy products were selected to evaluate the potential growth ability of the $2 \mathrm{~B}$. cereus strains: an unstructured fermented products with very low $\mathrm{pH}$ (yogurt, $\mathrm{pH}$ close to 4), neutral $\mathrm{pH}$

Table 1. Growth of Bacillus cereus GPe2 and D43 in nutrient broth at 2 different temperatures $\left(15\right.$ and $\left.37^{\circ} \mathrm{C}\right)$ recorded daily from $24 \mathrm{~h}$ postinoculation (T1) to $192 \mathrm{~h}(\mathrm{~T} 8)$ as difference in optical density (OD) ${ }^{1}$

\begin{tabular}{|c|c|c|c|c|c|c|c|c|c|}
\hline Strain and temperature & $\mathrm{pH}$ & $\mathrm{T} 1$ & $\mathrm{~T} 2$ & $\mathrm{~T} 3$ & $\mathrm{~T} 4$ & T5 & $\mathrm{T} 6$ & $\mathrm{~T} 7$ & $\mathrm{~T} 8$ \\
\hline \multicolumn{10}{|l|}{$\mathrm{GPe} 2$ at $15^{\circ} \mathrm{C}$} \\
\hline & 3.5 & - & - & - & - & - & - & - & - \\
\hline & 4 & - & - & - & - & - & - & - & - \\
\hline & 4.5 & - & - & - & - & - & - & - & - \\
\hline & 5 & - & - & - & - & - & - & - & - \\
\hline & 5.5 & - & - & - & - & + & ++ & ++ & +++ \\
\hline & 6 & - & - & - & ++ & +++ & +++ & +++ & +++ \\
\hline & 6.5 & - & - & + & ++ & ++ & ++ & ++ & ++ \\
\hline & 7 & - & - & - & +++ & +++ & +++ & +++ & +++ \\
\hline & 7.5 & - & - & - & +++ & +++ & +++ & ++ & ++ \\
\hline \multicolumn{10}{|l|}{$\mathrm{GPe} 2$ at $37^{\circ} \mathrm{C}$} \\
\hline & $\begin{array}{l}3.5 \\
4\end{array}$ & - & - & - & - & - & - & - & - \\
\hline & 4.5 & - & - & - & - & - & - & - & - \\
\hline & 5 & - & - & ++ & +++ & +++ & +++ & +++ & +++ \\
\hline & 5.5 & + & +++ & +++ & +++ & +++ & +++ & +++ & +++ \\
\hline & 6 & ++ & +++ & +++ & +++ & +++ & +++ & +++ & +++ \\
\hline & 6.5 & ++ & +++ & +++ & +++ & +++ & +++ & +++ & +++ \\
\hline & 7 & +++ & +++ & +++ & +++ & +++ & +++ & +++ & +++ \\
\hline & 7.5 & +++ & +++ & +++ & +++ & +++ & +++ & +++ & +++ \\
\hline \multicolumn{2}{|l|}{ D43 at $15^{\circ} \mathrm{C}$} & - & - & - & 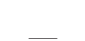 & 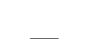 & - & - & - \\
\hline & $\begin{array}{l}0.0 \\
4\end{array}$ & - & - & - & - & - & - & - & - \\
\hline & 4.5 & - & - & - & - & - & - & - & - \\
\hline & 5 & - & - & - & - & - & - & - & - \\
\hline & 5.5 & - & - & - & - & - & - & - & - \\
\hline & 6 & - & - & - & + & ++ & + & + & + \\
\hline & 6.5 & - & - & - & +++ & +++ & ++ & ++ & +++ \\
\hline & 7 & - & - & - & +++ & +++ & ++ & ++ & +++ \\
\hline \multicolumn{10}{|l|}{ D43 at $37^{\circ} \mathrm{C}$} \\
\hline & 3.5 & - & - & - & - & - & - & - & - \\
\hline & 4 & - & - & - & - & - & - & - & - \\
\hline & 4.5 & - & - & - & - & - & - & - & - \\
\hline & 5 & - & + & +++ & ++ & +++ & +++ & +++ & +++ \\
\hline & 5.5 & + & +++ & +++ & +++ & +++ & +++ & +++ & +++ \\
\hline & 6 & +++ & +++ & +++ & +++ & +++ & +++ & +++ & +++ \\
\hline & 6.5 & +++ & +++ & +++ & +++ & +++ & +++ & +++ & +++ \\
\hline & 7 & +++ & +++ & +++ & +++ & +++ & +++ & +++ & +++ \\
\hline & 7.5 & +++ & +++ & +++ & +++ & +++ & +++ & +++ & +++ \\
\hline
\end{tabular}

${ }^{1}+$ : increase $<0.2$ OD if compared with the equivalent blank sample. ++ : increase between 0.2 and 0.5 OD if compared with the equivalent blank sample. +++ : increase $>0.5$ OD if compared with the equivalent blank sample. 
products without structure (raw and pasteurized milk, $\mathrm{pH}$ around 6.7/6.9), and weakly acid $\mathrm{pH}$ structured products with and without natural microflora (Taleggio cheese and mascarpone cheese, $\mathrm{pH} \sim 6$ ). In all the blank samples analyzed, B. cereus was always below the detection limit of $2 \mathrm{log} \mathrm{cfu} / \mathrm{g}$.

Considering unflavored yogurt, very low $\mathrm{pH}$ values were detected (between 3.85 and 4.08 in the 2 series of samples) with a slight acidification in the last sampling time, but with no clear trends during the whole storage period. Such low values did not allow the growth of both $B$. cereus strains inoculated, resulting in stable bacterial concentrations (increase in both the strains $<0.5 \log \mathrm{cfu} / \mathrm{g}$ from the day of inoculation until after 5 $\mathrm{d}$ of storage) without statistical differences between the strains (Figure 1). The $\mathrm{a}_{\mathrm{w}}$ measured at T0 was 0.981, therefore not limiting bacterial growth. The total numbers of vegetative cells and spores were very similar to those of the spores alone (at T5, D43 total $=3.88 \pm$ $0.13 \log \mathrm{cfu} / \mathrm{g}$ vs. spores $=3.85 \pm 0.00 ; \mathrm{GPe} 2$ total $=$ $4.43 \pm 0.491$ vs. spores $=3.90 \pm 0.01 \log \mathrm{cfu} / \mathrm{g}$ ); thus, the colonies could be considered spores that did not find ideal conditions for germination during the period considered. During the experimental period, LAB and lactococci were always above $6 \mathrm{log} \mathrm{cfu} / \mathrm{g}$ singularly and above $7 \log \mathrm{cfu} / \mathrm{g}$ in combination, as required by the UNI 10358 rule for the definition of yogurt (Uni Ente Italiano di Normazione, 1993). The role of these microorganisms is crucial in determining the absence of $B$. cereus growth, which can be attributed to the mixed effect exerted by the bacterial competition and $\mathrm{pH}$ lowering due to lactic acid production. As expected, yogurt is not an optimal substrate for B. cereus growth, as already demonstrated for other pathogens (Tirloni et al., 2015); its presence in the product with small prevalence rates was already proven $(\sim 1 \%$ according to Hassan et al., 2010), but if the concentration does not exceed $4 \log \mathrm{cfu} / \mathrm{g}$, no risk should be considered for consumers thanks to this inability to replicate. Bacillus cereus was demonstrated to be able to cause disease with loads between 4 and $8 \mathrm{log} \mathrm{cfu} / \mathrm{g}$ of food; nevertheless, this range may be even wider, due to possible differences in toxin production and specific growth rate among specific strains.

In Taleggio cheese, $\mathrm{pH}$ values were variable but always permissive, between 5.8 and 6.8 without any particular trend in both of the series during the trial. The $\mathrm{a}_{\mathrm{w}}$ measured $(\mathrm{T} 0=0.960)$ was not a preventive factor. However, also in this substrate, no B. cereus GPe2 and D43 growth was detected, with a significantly higher decrease in GPe2 compared with $\mathrm{D} 43 \quad(P=0.049$; D43: $\mathrm{T} 0=3.48 \pm 0.00, \mathrm{~T} 5=3.29 \pm 0.83 \log \mathrm{cfu} / \mathrm{g}$; GPe2: T0 $=3.75 \pm 0.17, \mathrm{~T} 5=3.40 \pm 0.64 \log \mathrm{cfu} / \mathrm{g}$ ); this could be probably due to the action of the natu- ral microflora present, mainly composed by LAB. In fact, rapid growth of LAB in this matrix was observed, reaching $7.5 \pm 0.2 \log \mathrm{cfu} / \mathrm{g}$ after $5 \mathrm{~d}$ of storage at $15^{\circ} \mathrm{C}$; thus, a role in competition for nutrients could be hypothesized. Although substrate acidity in association with the presence of LAB is probably the main factor for the preservation of lactic acid-fermented foods like yogurt and starter culture dairy products like Taleggio cheese, the nature of this inhibition should be further studied as several other factors may also be important, such as the production of bacteriocins, diacetyl, carbon dioxide, hydrogen peroxide, and ethanol (Holzapfel et al., 1995; Tirloni et al., 2014). Inhibition of B. cereus by LAB has been already reported in milk medium, in Gouda cheese and in Brie (Wong and Chen, 1988; Little and Knøchel, 1994; Rukure and Bester, 2001).

In mascarpone cheese, the absence of hurdles such as a low $\mathrm{pH}$ (range from 5.87 to 6.27 ), a low $\mathrm{a}_{\mathrm{w}}$ ( $\mathrm{T} 0=$ 0.967 ), or the presence of natural microflora inhibiting pathogen growth allowed the rapid germination of $B$. cereus spores and a very fast increase in the counts at $15^{\circ} \mathrm{C}$. After $5 \mathrm{~d}$ of storage, B. cereus GPe2 and D43 reached loads equal to 7.59 and $7.71 \mathrm{log} \mathrm{cfu} / \mathrm{g}$, respectively (an increase equal to 5.05 and $4.89 \mathrm{log} \mathrm{cfu} / \mathrm{g}$, respectively) without significant differences among the 2 B. cereus strains (Figure 2). These counts should be carefully considered, especially if mascarpone cheese, as habitually occurs, is used as a component of dessert (e.g., tiramisu). Typically, these preparations can be maintained for more than $1 \mathrm{~d}$ in the cooled shelves of restaurants where the internal temperature could increase above optimal temperatures, especially during the warm season.

Considering raw and pasteurized milk, noteworthy differences were found in $B$. cereus growth comparing the 2 substrates for both the inoculated series (Figure 3 ). In pasteurized milk, growth of D43 and GPe2 occurred since the first day of storage, reaching the loads of $6.56 \pm 0.48$ and $6.79 \pm 0.02 \mathrm{log} \mathrm{cfu} / \mathrm{g}$, respectively, after $5 \mathrm{~d}$, without significant differences between the two, although D43 showed an earlier active increase in bacterial concentration.

In raw milk inoculated with D43 and GPe2 series, no growth was detected. In particular, growth suppression was evident with most of the samples (2 GPe2 and 1 D43 inoculated samples) being below the detection limit of $2 \log \mathrm{cfu} / \mathrm{g}$ after $5 \mathrm{~d}$. The decrease of bacterial concentration, even if not significantly different among the 2 strains, was faster in Gpe2.

The difference between raw an pasteurized milk could be due to the presence, in raw milk, of limiting factors (e.g., acidity of substrates with $\mathrm{pH}$ that decrease from 6.84 to 4.56 at the end of the trial, high levels of natural microflora) that cannot exert any action in 
pasteurized milk. The role of natural microbial population seems to be critical, as the milk microflora could couple a competitive exclusion with the modification (acidification) of the environment. It has been stated that cheese microbiota, whose community composition is in continuous evolution, may play a key role in $\mathrm{B}$. cereus inhibition (Irlinger and Mounier, 2009); our results on raw milk are in agreement with those reported by Necidová et al. (2014) that found a suppression of B. cereus growth and toxin production in cow raw milk. The growth inhibition operated by the presence of high bacterial concentrations in a substrate is mentioned as the Jameson effect, after Jameson (1962), which described the complete inhibition of Escherichia coli when the maximum population density of another microorganism was reached. Many other studies reported the same conclusion in broth and dairy products, describing the nutrient limitation as a consequence of the growth of the dominant microflora, which consumed all the molecules that are also required by other species (Mellefont et al., 2008; Østergaard et al., 2014). In the raw milk samples analyzed in this study, the inhibitory effect was likely due to LAB that reached a high level ( $\sim 6 \log \mathrm{cfu} /$ $\mathrm{mL}$ ) after $5 \mathrm{~d}$ of storage. The mechanism of action of LAB against $B$. cereus strains is not completely clear, due to the extreme variability of microbiota of dairy

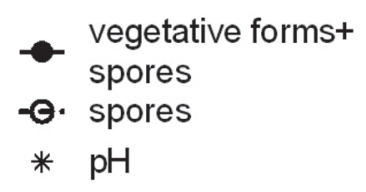

Taleggio Cheese D43

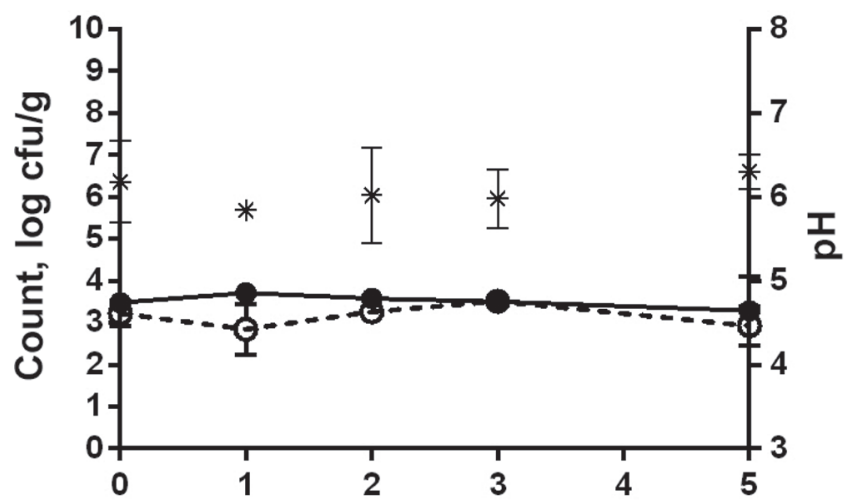

Yogurt D43

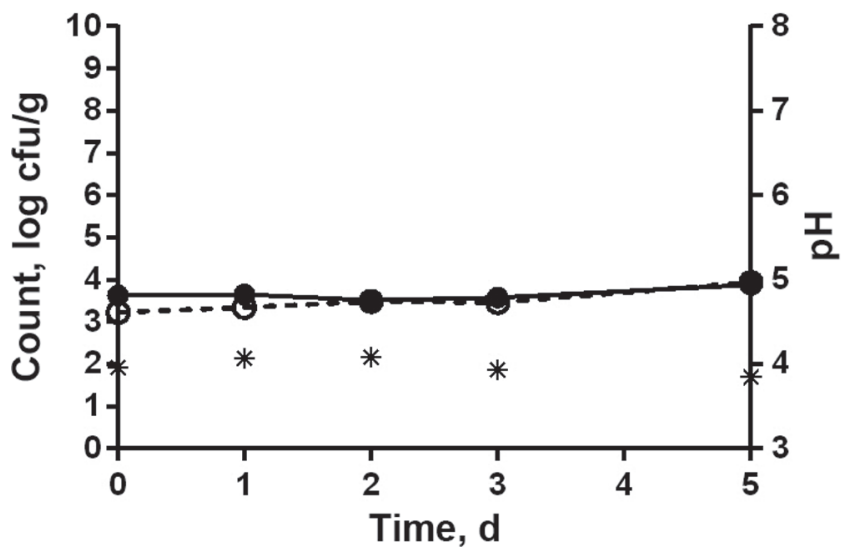

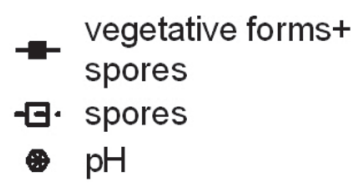

\section{Taleggio Cheese GPe2}

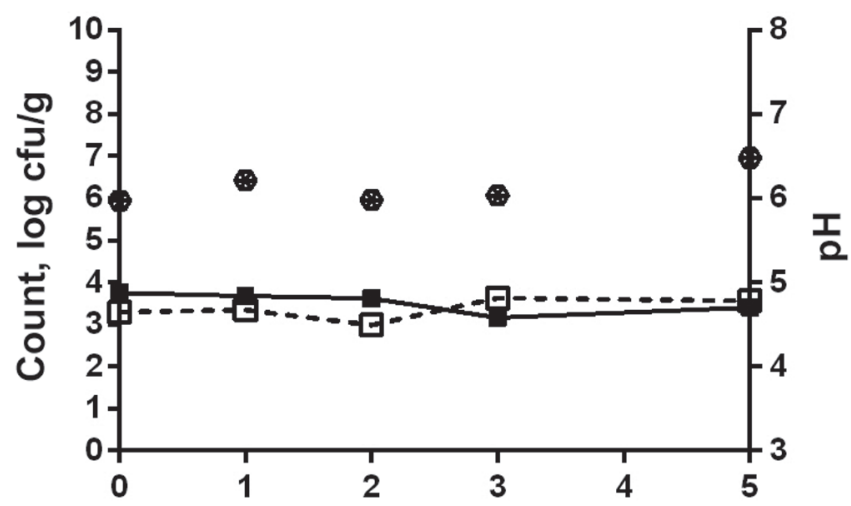

Yogurt GPe2

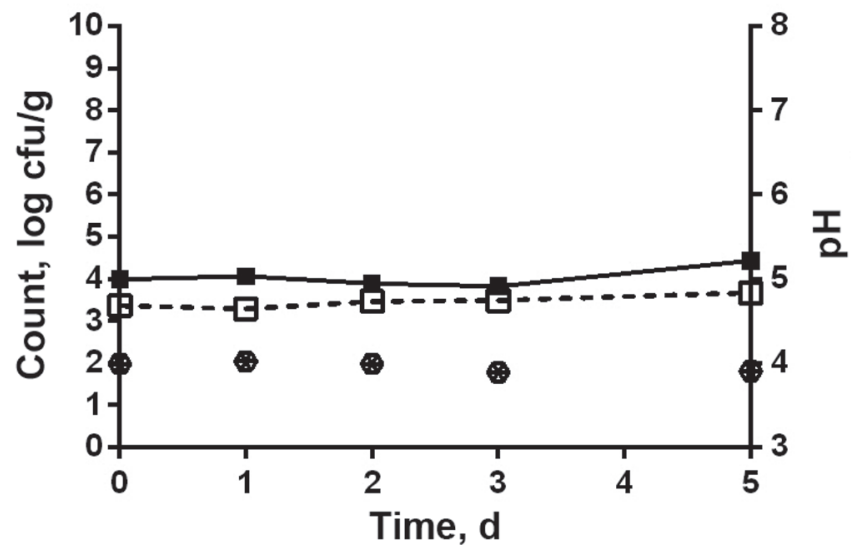

Figure 1. Mean counts of Bacillus cereus GPe2 and D43 and their spores inoculated in Taleggio cheese and unflavored yogurt stored at $15^{\circ} \mathrm{C}$ for up to $5 \mathrm{~d}$ (sampling times at T0 d of inoculation, T1 after $24 \mathrm{~h}$, T2 after $48 \mathrm{~h}$, T3 after $72 \mathrm{~h}$, and T5 after $120 \mathrm{~h}$ of storage). The pH values are also reported for each sampling time (refers to right axis). Error bars indicate SD. 
products and their highly heterogeneous composition that gives the opportunity for the concurrent occupation by specialized strains of different ecological niches (Irlinger and Mounier, 2009).

The role of the temperature seems to be not critical for the growth of the 2 strains in the products; as a matter of fact, also if the test was performed at the minimum temperature allowing $B$. cereus growth in broth, the characteristics of the substrate resulted in total absence of germination/growth (acidic and competitive environment) or in a fast growth (neutral and microflora-free environment).

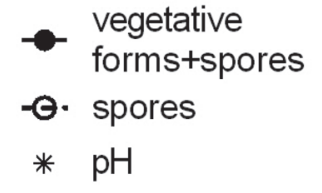

\section{Raw milk D43}

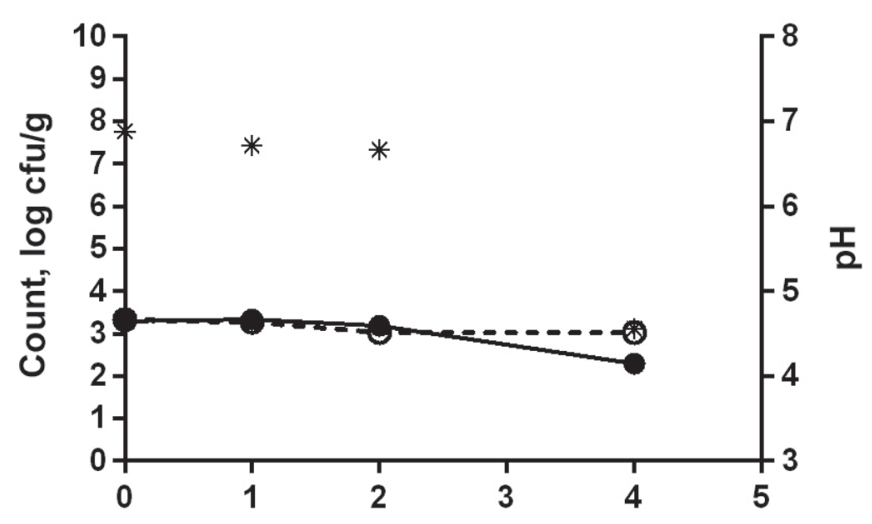

\section{Pasteurized milk D43}

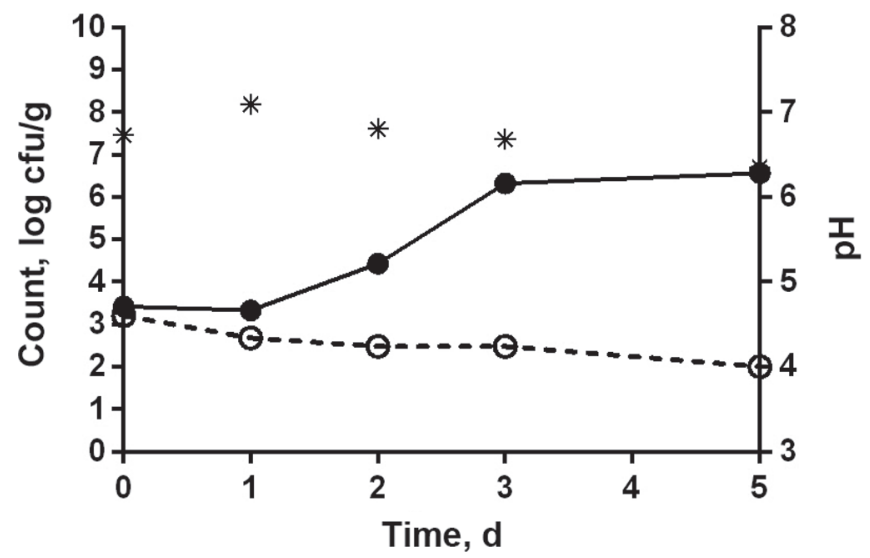

Finally, the comparison of the $2 B$. cereus strains used for the trials, isolated from different sources (human or dairy) did not reveal a significant difference in growth ability in the tested milk and dairy products samples, although in some cases D43 showed a better resistance, allowing to hypothesize its major ability to survive and growth when possible in dairy substrates.

A specificity in the viability and growth of different B. cereus strains has already been demonstrated (Guinebretière et al., 2008; Shen et al., 2008; Tirloni et al., 2017); our findings could be explained in different ways. First, the environmental conditions of the

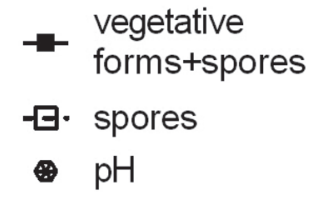

Raw milk GPe2

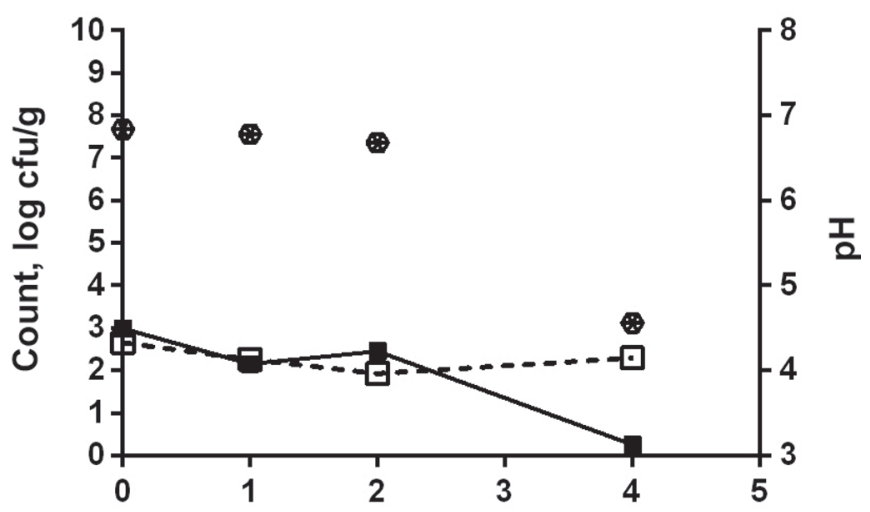

Pasteurized milk GPe2

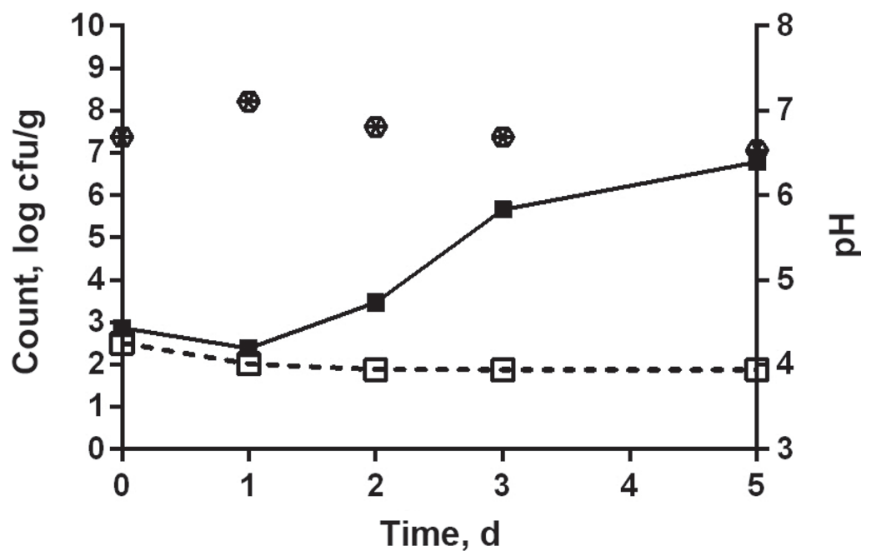

Figure 2. Mean counts of Bacillus cereus GPe2 and D43 and their spores inoculated in raw and pasteurized milk stored at $15^{\circ} \mathrm{C}$ for up to 4 $\mathrm{d}$ (sampling times at T0 d of inoculation, T1 after $24 \mathrm{~h}$, and T4 after $96 \mathrm{~h}$ of storage). The $\mathrm{pH}$ values are also reported for each sampling time (refers to right axis). 


$$
\begin{aligned}
& \text { - } \begin{array}{l}
\text { vegetative } \\
\text { forms+spores }
\end{array} \\
& \text { ๑. spores } \\
& \text { * pH }
\end{aligned}
$$

\section{Mascarpone D43}

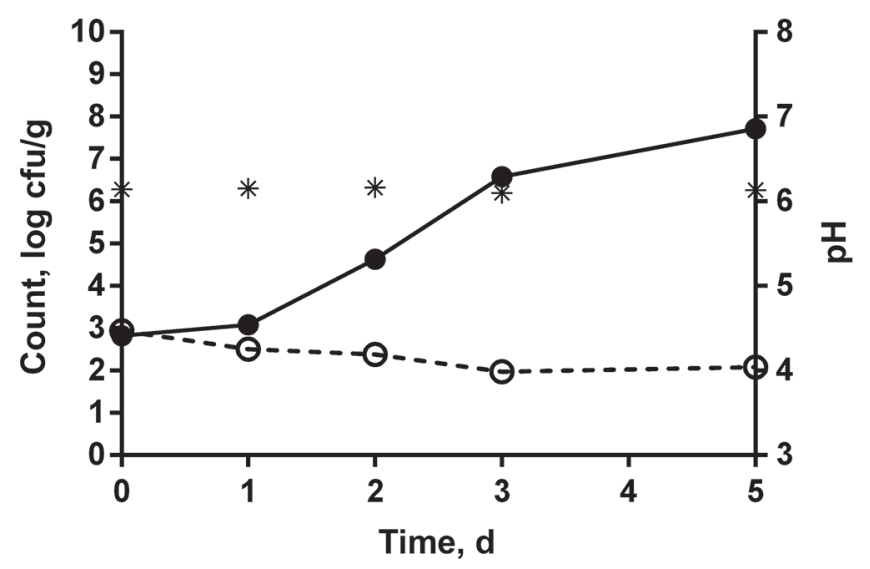

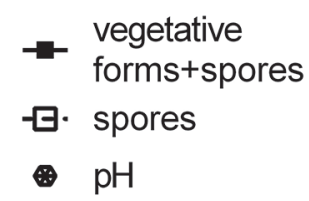

Mascarpone GPe2

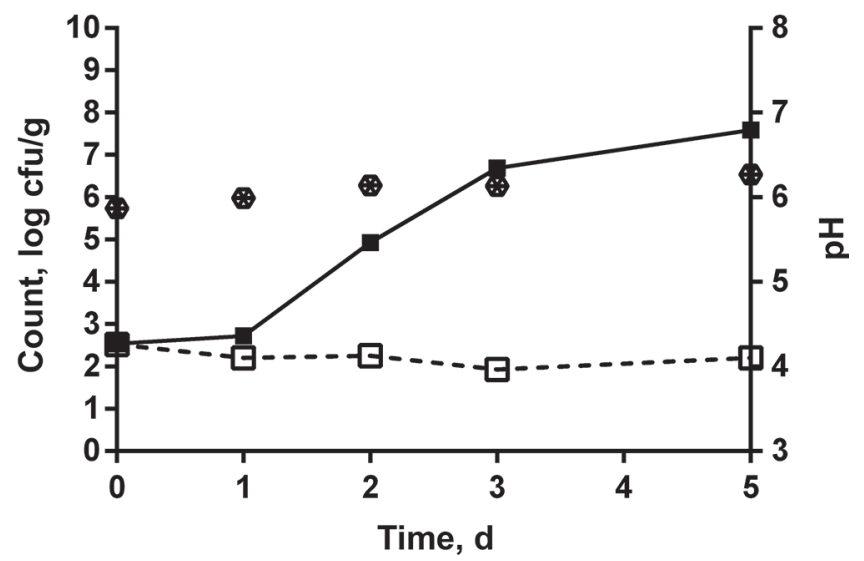

Figure 3. Mean counts of Bacillus cereus GPe2 and D43 and their spores inoculated in mascarpone cheese stored at $15^{\circ} \mathrm{C}$ for up to 5 d (sampling times at T0 d of inoculation, T1 after $24 \mathrm{~h}$, T2 after $48 \mathrm{~h}$, T3 after $72 \mathrm{~h}$, and T5 after $120 \mathrm{~h}$ of storage). The pH values are also reported for each sampling time (refers to right axis).

substrates tested could be not near the growth boundary of these strains, so resulting in complete inhibition (yogurt and Taleggio cheese) or absence of significant limiting factors (pasteurized milk and mascarpone cheese). Then, the thermal range of growth of the 2 isolates was assessed to be the same, so the influence of the temperature used for the trials should exert the same metabolic effect on them.

\section{CONCLUSIONS}

Generally, dairy products are extremely susceptible to $B$. cereus contamination because of the natural presence of the bacterium in the environment, thus enabling the contamination of raw matter, and postpasteurization or postproduction contamination. Nevertheless, many environmental conditions (such as $\mathrm{pH}, \mathrm{a}_{\mathrm{w}}$, and natural/added microflora) can affect the growth of this microorganism during storage. In the foodstuffs considered in our study, $\mathrm{pH}$ and the presence of dense LAB microflora were crucial in products such as unflavored yogurt, Taleggio cheese, and raw milk for inhibiting germination of B. cereus spores and subsequent growth of vegetative cells. In pasteurized milk and mascarpone cheese, where $\mathrm{pH}$ was permissive for growth and a very limited microflora was present due to the heat treatments during production, rapid growth of the bacterium occurred, reaching levels of concern. Thus, especially for these types of products, correct hygienic procedures should be constantly applied during the production process to reduce the risk of contamination by ubiquitous, resistant, and potentially pathogenic $B$. cereus strains.

\section{REFERENCES}

ANSES. 2014. EURL Lm European Union Reference Laboratory for Listeria monocytogenes, 2014. EURL Lm Technical Guidance Document for conducting shelf-life studies on Listeria monocytogenes in ready-to-eat foods. Version 3. Accessed Mar. 30, 2017. https://sites.anses.fr/en/system/files/private/EURL\%20Lm _Technical\%20Guidance\%20Document\%20Lm\%20shelf-life \%20 studies_V3_2014-06-06.pdf.

Bartoszewicz, M., B. M. Hansen, and I. Swiecick. 2008. The members of the Bacillus cereus group are commonly present contaminants of fresh and heat-treated milk. Food Microbiol. 25:588-596.

Carlin, F., C. Albagnac, A. Rida, M.-H. Guinebretière, O. Couvert, and C. Nguyen-The. 2013. Variation of cardinal growth parameters and growth limits according to phylogenetic affiliation in the Bacillus cereus group. Consequences for risk assessment. Food Microbiol. 33:69-76.

Celandroni, F., S. Salvetti, S. A. Gueye, D. Mazzantini, A. Lupetti, S. Senesi, and E. Ghelardi. 2016. Identification and pathogenic potential of clinical Bacillus and Paenibacillus isolates. PLoS One 11:e0152831. 10.1371/journal.pone.0152831.

Claus, D., and R. C. W. Berkeley. 1986. Genus Bacillus Cohn 1872. Pages 1105-1139 in Bergey's Manual of Systematic Bacteriology, Vol. 1. P. H. A. Sneath, N. S. Mair, M. E. Sharpe, and J. G. Holt, ed. Williams \& Wilkins, Baltimore, MD.

European Food Safety Authority (EFSA). 2016. Risks for public health related to the presence of Bacillus cereus and other Bacillus spp. including Bacillus thuringiensis in foodstuffs. EFSA J. 14:4524. 
Granum, P. E., S. Brynestad, and J. M. Kramer. 1993. Analysis of enterotoxin production by Bacillus cereus from dairy products, food poisoning incidents and non-gastrointestinal infections. Int. J. Food Microbiol. 17:269-279.

Guérin, A., C. Dargaignaratz, V. Broussolle, T. Clavel, and C. Nguyen-the. 2016. Combined effect of anaerobiosis, low $\mathrm{pH}$ and cold temperatures on the growth capacities of psychrotrophic Bacillus cereus. Food Microbiol. 59:119-123.

Guinebretière, M. H., F. L. Thompson, A. Sorokin, P. Normand, P. Dawyndt, M. Ehling-Schulz, B. Svensson, V. Sanchis, C. NguyenThe, M. Heyndrickx, and P. De Vos. 2008. Ecological diversification in the Bacillus cereus Group. Environ. Microbiol. 10:851-865.

Hassan, G. M., M. A. M. Al-Ashmawy, A. M. S. Meshref, and S. I Afify. 2010. Studies on enterotoxigenic Bacillus cereus in raw milk and some dairy products. J. Food Saf. 30:569-583.

Holzapfel, W. H., R. Geisen, and U. Schillinger. 1995. Biological preservation of foods with reference to protective cultures, bacteriocins and food-grade enzymes. Int. J. Food Microbiol. 24:343-362.

in't Veld, P. H., W. S. Ritmeester, E. H. M. Delfgou-van Asch, J. B. Dufrenne, K. Wernars, E. Smit, and F. M. Van Leusden. 2001. Detection of genes encoding for enterotoxins and determination of the production of enterotoxins by HBL blood plates and immunoassays of psychrotrophic strains of Bacillus cereus isolated from pasteurized milk. Int. J. Food Microbiol. 64:63-70.

International Commission for the Microbiological Specifications for Foods (ICMSF). 2005. Bacillus cereus. Pages 20-35 in Microbiological Specifications of Food Pathogens, Microorganisms in Foods, Vol. 5. Blackie Academic and Professional, London, UK.

International Organization for Standardisation (ISO). 1998. Microbiology of food and animal feeding stuffs-Horizontal 329 method for the enumeration of mesophilic lactic acid bacteria-Colony-count technique at 30 degrees C. ISO 330 15214:1998. ISO, Geneva, Switzerland.

International Organization for Standardisation (ISO). 2004. Microbiology of food and animal feeding stuffs-Horizontal method for the enumeration of presumptive Bacillus cereus-Colony-count technique at 30 degrees C. ISO 7932:2004. ISO, Geneva, Switzerland.

Irlinger, F., and J. Mounier. 2009. Microbial interactions in cheese: Implications for cheese quality and safety. Curr. Opin. Biotechnol. $20: 142-148$.

Jameson, J. E. 1962. A discussion of the dynamics of Salmonella enrichment. J. Hyg. (Lond.) 60:193-207.

Kotiranta, A., K. Lounatmaa, and M. Haapasalo. 2000. Epidemiology and pathogenesis of Bacillus cereus infections. Microbes Infect. 2:189-198.

Leyer, G. J., and E. A. Johnson. 1992. Acid adaptation promotes survival of Salmonella spp. in cheese. Appl. Environ. Microbiol. 58:2075-2080

Little, C. L., and S. Knøchel. 1994. Growth and survival of Yersinia enterocolitica, Salmonella and Bacillus cereus in Brie stored at 4,8 and $20^{\circ} \mathrm{C}$. Int. J. Food Microbiol. 24:137-145.

Mellefont, L. A., T. A. McMeekin, and T. Ross. 2008. Effect of relative inoculum concentration on Listeria monocytogenes growth in co-culture. Int. J. Food Microbiol. 121:157-168.

Necidová, L., Š. Bursová, A. Skočková, B. Janštová, P. Prachařová, Ž. Ševčíková, and B. Janštová. 2014. Growth and enterotoxin production of Bacillus cereus in cow, goat, and sheep milk. Acta Vet. Brno 83:3-8
Notermans, S., J. Dufrenne, P. Teunis, R. Beumer, T. te Giffel, and P. P. Weem. 1997. A risk assessment study of Bacillus cereus present in pasteurized milk. Food Microbiol. 14:143-151.

Østergaard, N. B., A. Eklöw, and P. Dalgaard. 2014. Modelling the effect of lactic acid bacteria from starter- and aroma culture on growth of Listeria monocytogenes in cottage cheese. Int. J. Food Microbiol. 188:15-25.

Raevuori, M., and C. Genigeorgis. 1975. Effect of pH and sodium chloride on growth of Bacillus cereus in laboratory media and certain foods. Appl. Microbiol. 29:68-73.

Rukure, G., and B. H. Bester. 2001. Survival and growth of Bacillus cereus during Gouda cheese manufacturing. Food Contr. 12:31-36.

Senesi, S., G. Cercignani, G. Freer, G. Batoni, S. Barnini, and F. Ota. 1991. Structural and stereospecific requirements 366 for the nucleoside-triggered germination of Bacillus cereus spores. J. Gen. Microbiol. 137:399-404.

Shen, H. W., R. C. Yu, and C. C. Chou. 2008. Viability of acidadapted and non-adapted Bacillus cereus during the lactic fermentation of skim milk and product storage at $5^{\circ} \mathrm{C}$. J. Food Dru. Anal. 16:88-94.

Spanu, C., C. Scarano, V. Spanu, C. Pala, D. Casti, S. Lamon, F. Cossu, M. Ibba, G. Nieddu, and E. P. L. De Santis. 2016. Occurrence and behavior of Bacillus cereus in naturally contaminated ricotta salata cheese during refrigerated storage. Food Microbiol. 58:135-138.

Stenfors Arnesen, L. P., A. Fagerlund, and P. E. Granum. 2008. From soil to gut: Bacillus cereus and its food poisoning toxins. FEMS Microbiol. Rev. 32:579-606.

Svensson, B., A. Monthán, R. Shaheen, M. A. Andersson, M. Salkinoja-Salonen, and A. Christiansson. 2006. Occurrence of emetic toxin producing Bacillus cereus in the dairy production chain. Int. Dairy J. 16:740-749.

Tirloni, E., C. Bernardi, F. Colombo, and S. Stella. 2015. Microbiological shelf life at different temperatures and fate of Listeria monocytogenes and Escherichia coli inoculated in unflavored and strawberry yogurts. J. Dairy Sci. 98:4318-4327.

Tirloni, E., P. Cattaneo, B. Ripamonti, A. Agazzi, C. Bersani, and S. Stella. 2014. In vitro evaluation of Lactobacillus animalis SB310, Lactobacillus paracasei ssp. paracasei SB137 and their mixtures as potential bioprotective agents for raw meat. Food Contr. 41:63-68.

Tirloni, E., E. Ghelardi, F. Celandroni, C. Bernardi, R. Casati, P. S. Rosshaug, and S. Stella. 2017. Bacillus cereus in fresh ricotta: Comparison of growth and Haemolysin BL production after artificial contamination during production or post processing. Food Contr. 79:272-278.

Uni Ente Italiano di Normazione. 1993. Yogurt e yogurt con aggiunta di altri ingredienti alimentari. Definizione, composizione e caratteristiche. Norma Uni 10358.

Wijnands, L. M., J. B. Dufrenne, F. M. Rombouts, P. H. in 't Veld, and F. M. van Leusden. 2006. Prevalence of potentially pathogenic Bacillus cereus in food commodities in The Netherlands. J. Food Prot. 69:2587-2594.

Wong, H. C., and Y. Chen. 1988. Effects of lactic acid bacteria and organic acids on growth and germination of Bacillus cereus. Appl. Environ. Microbiol. 54:2179-2184.

Wong, H. C., L. Y. Chen, and C. L. Chen. 1988. Growth germination and toxigenic activity of Bacillus cereus in milk products. J. Food Prot. 51:707-710 